\title{
Removal of ammonium from aqueous solutions using zeolite synthesized from fly ash by a fusion method
}

\author{
Mulan Zhang a, Huayong Zhang a,*, Dan Xu ${ }^{\text {a }}$, Lu Han ${ }^{\text {b }}$, Dongxiao Niu ${ }^{\text {c }}$, Binghui Tian ${ }^{\text {d, Jian Zhang }}$, \\ Luyi Zhang a , Wensi $\mathrm{Wu}^{\mathrm{a}}$ \\ a Research Center for Ecological Engineering and Nonlinear Science, North China Electric Power University, Beijing, 102206, China \\ b Industrial Systems Engineering, University of Regina, 3737 Wascana Parkway, Regina, Saskatchewan, S4S 0A2, Canada \\ c School of Business and Management, North China Electric Power University, Beijing 102206, China \\ d State Key Laboratory of Environmental Aquatic Chemistry, Research Center for Eco-environmental Sciences, Chinese Academy of Sciences, Beijing 100085, China \\ e School of Environmental Science and Engineering, Shandong University, Jinan 250100, China
}

\section{A R T I C L E I N F O}

\section{Article history:}

Received 10 September 2010

Received in revised form 6 December 2010

Accepted 7 December 2010

Available online 8 January 2011

\section{Keywords:}

Fly ash

Synthesized zeolite

Fusion method

Ammonium

Ion exchange

\begin{abstract}
A B S T R A C T
This article investigates the removal of ammonium from aqueous solutions using zeolite synthesized from fly ash by a fusion method, which combines alkaline fusion followed by hydrothermal treatment. The cation exchange capacity increases from 0.03 to $2.79 \mathrm{meq} / \mathrm{g}$ during the synthesis process. The effects of contact time, $\mathrm{pH}$, initial ammonium concentration, adsorbent dosage, and the presence of other cations and anions are examined by batch experiments. The findings show that these parameters have significant effects on the ammonium removal using the synthesized zeolite. The effect of cations follows the order $\mathrm{K}^{+}>\mathrm{Ca}^{2+}>\mathrm{Na}^{+}>\mathrm{Mg}^{2+}$, while the effect of anions follows the order $\mathrm{CO}_{3}^{2-}>\mathrm{Cl}^{-}>\mathrm{SO}_{4}^{2-}$. The Lagergren first-order, $\mathrm{Ho}$ ' pseudo-second-order, and intraparticle diffusion kinetic models are employed to describe the kinetic data, and Ho' pseudo-second-order model provides excellent fitting. The equilibrium isotherm data are fitted to the Langmuir, Freundlich, Koble-Corrigan, Tempkin and Dubinin-Radushkevich models; the Koble-Corrigan model gives the best fit. The thermodynamic study reveals that ammonium uptake by the synthesized zeolite is an exothermic reaction. The maximum ammonium uptake capacity obtained is $24.3 \mathrm{mg} / \mathrm{g}$. The regenerated zeolite has almost the same ammonium uptake capacity as the original zeolite. These results indicate that the synthesized zeolite is a promising material for removing ammonium from wastewater.
\end{abstract}

(C) 2010 Elsevier B.V. All rights reserved.

\section{Introduction}

Ammonium is the primary form of widespread nitrogen pollution in the hydrosphere [1]. Increased accumulation of ammonium not only leads to eutrophication in lakes, ponds, and reservoirs, but also increases the oxygen demand and exposes toxicity to aquatic life [2-4]. Following increased awareness of the deleterious effects of ammonium, stringent laws restricting ammonium discharged from wastewater have been established in many countries. For example, for municipal wastewater treatment plants in China, the discharge standard of ammonium was set to $5 \mathrm{mg} / \mathrm{L}$ for Class I effluent and $8 \mathrm{mg} / \mathrm{L}$ for Class II effluent [5]. The removal of ammonium from municipal and industrial wastewater prior to discharge is now obligatory.

Various methods, including biological technology (nitrificationdenitrification), air stripping, and ion exchange, have been used for ammonium removal [6-8]. Among these, ion exchange with zeolites, a

\footnotetext{
* Corresponding author. Tel.: +86 10 51971230; fax: +86 1051971244 . E-mail address: bjecology@gmail.com (H. Zhang).
}

low-cost and effective method, has been widely used in various types of wastewater treatment for the removal of ammonium $[9,10]$. Zeolites are hydrated aluminum-silicate minerals with cation exchange capacity and affinity for ammonium [10]. A number of natural zeolites exhibit strong ability to remove ammonium from aqueous solutions [11,12].

Fly ash is a waste material generated from electric power plants. The generation rate of fly ash is approximately 500 million tons per year worldwide and it is predicted to increase [13]. Except for a small proportion of fly ash used as a building material, most of it is disposed in piles and landfills, causing severe environmental problems. As an environmental friendly application of fly ash, the synthesis of zeolite from this material has been paid increasing attention in recent years. Zeolite synthesized from such a material has better pollutant-removing abilities than natural zeolite due to the high zeolite content in the former [14]. The use of zeolite synthesized from fly ash in ammonium removal has been reported in the literature [15-17]. Juan et al. [15] synthesized zeolite from fly ash by alkali hydrothermal treatment, and found that the obtained material effectively removed ammonium from wastewater produced by a sewage treatment plant. Using salt treatment, Wu et al. [17] improved the ammonium removal capacity of zeolite synthesized from fly ash. In these studies, however, the zeolites were synthesized 
from fly ash using a conventional hydrothermal method. The obtained materials contained a considerable amount of fly ash residue, thus fundamentally limiting their adsorption capacity [18]. The fusion method suggested by Shigemoto et al. [19] includes an alkaline fusion stage prior to the conventional hydrothermal process, and can turn fly ash into high purity zeolite. Previous studies have also shown that zeolite synthesized from fly ash using this method has higher crystallinity and cation exchange capacity (CEC) compared to zeolite synthesized using the conventional hydrothermal method [20]. Few investigations have been conducted on the performance of zeolite synthesized from fly ash by the fusion method in ammonium removal.

The aim of the present study is to examine the ability of zeolite synthesized from fly ash using the fusion method to remove ammonium from aqueous solutions. The influences of contact time, $\mathrm{pH}$ value, initial ammonium concentration, adsorbent dosage, and the individual presence of cationic and anionic species are investigated to determine the optimal uptake conditions. The adsorption kinetics, equilibrium isotherms, and thermodynamics of the uptake of ammonium by the synthesized zeolite are also studied.

\section{Materials and methods}

\subsection{Zeolite synthesis}

The fly ash used in this study was obtained from a power plant located in Yunnan Province, China. The chemical composition of the fly ash is listed in Table 1 . Based on a previous study [18,21], a fusion method, involving alkaline fusion followed by hydrothermal treatment, was adopted for the synthesis of zeolite. Nine grams of fly ash were mixed with $\mathrm{NaOH}$ powder (analytical reagent grade) to obtain a homogeneous mixture. The ratio of fly ash to $\mathrm{NaOH}$ was $1: 1.3(\mathrm{w} / \mathrm{w})$. The mixture was then heated in a nickel crucible in air at $600{ }^{\circ} \mathrm{C}$ for $90 \mathrm{~min}$. The fusion products were ground and poured into a plastic bottle, followed by the addition of distilled water to form a mixture that contains $17.25 \%$ of the fusion product $(\mathrm{w} / \mathrm{w})$. The mixture was stirred intensely at $80^{\circ} \mathrm{C}$ for $1 \mathrm{~h}$ to form an aluminosilicate gel, and then poured into a stainless alloy autoclave and kept in oven at $100{ }^{\circ} \mathrm{C}$ for $9 \mathrm{~h}$. After hydrothermal treatment, the precipitated samples were extracted and washed with distilled water until the $\mathrm{pH}$ of the samples was about 9 . The samples were dried at $100{ }^{\circ} \mathrm{C}$ for $12 \mathrm{~h}$ and sieved through a 100 mesh $(<150 \mu \mathrm{m})$ for further studies.

\subsection{Physical and chemical characterization}

The identification of crystalline materials in the fly ash and synthesized zeolite was carried out using X-ray diffraction (XRD) equipment (Rikaku D/max-RB, Rikaku, Japan). Scattering patterns were collected from $2.6^{\circ}$ to $45^{\circ}$ at a scan time of 1 min per 2 steps. The morphological structures of the two materials mentioned above were obtained using a scanning electron microscope (SEM) (S-3000N, Hitachi, Japan).

The specific surface area (SSA) of the fly ash and synthesized zeolite was determined by the nitrogen adsorption method. Nitrogen sorption experiments were carried out at $77 \mathrm{~K}$ using QuadraSorb SI

Table 1

Chemical composition of fly ash (wt.\%).

\begin{tabular}{lc}
\hline Component & Content (\%) \\
\hline $\mathrm{SiO}_{2}$ & 75.69 \\
$\mathrm{Al}_{2} \mathrm{O}_{3}$ & 6.43 \\
$\mathrm{Fe}_{2} \mathrm{O}_{3}$ & 5.45 \\
$\mathrm{~K}_{2} \mathrm{O}$ & 0.07 \\
$\mathrm{CaO}$ & 3.31 \\
$\mathrm{MgO}$ & 0.12 \\
$\mathrm{Na}_{2} \mathrm{O}$ & 0.51 \\
$\mathrm{MnO}$ & 0.41 \\
\hline
\end{tabular}

(Cantata Instruments Co., USA). Prior to the determination of the adsorption isotherm, about $3.0 \mathrm{~g}$ of fly ash and $0.1 \mathrm{~g}$ of the synthesized zeolite were first outgassed at $200{ }^{\circ} \mathrm{C}$ under vacuum for $2 \mathrm{~h}$. The samples were then immersed in liquid nitrogen at $77 \mathrm{~K}$ before the sorption measurements were taken. The BET equation was applied to determine the SSA.

The CECs of the fly ash and synthesized zeolite were measured according to Chen et al. [22]. About $0.5 \mathrm{~g}$ of the samples was mixed with $25 \mathrm{~mL}$ of ammonium acetate $(1 \mathrm{~mol} / \mathrm{L})$ thrice to exchange the cations of the samples with the ammonium ion. After continuous stirring for $1.5 \mathrm{~h}$ at $25^{\circ} \mathrm{C}$, the resulting mixtures were centrifuged. The solid residues were then washed thrice with $25 \mathrm{~mL}$ of ethanol (95\%) to remove excess bound ammonium acetate on the zeolite. The obtained ammonium-saturated solid residues were mixed thrice with $25 \mathrm{~mL}$ of $\mathrm{CaCl}_{2}(0.5 \mathrm{~mol} / \mathrm{L})$ to extract the ammonium ion using $\mathrm{Ca}^{2+}$. After continuous stirring for $1.5 \mathrm{~h}$ at $25^{\circ} \mathrm{C}$, the obtained suspensions were filtered with a $0.45 \mu \mathrm{m}$ cellulose acetate membrane. The extracted ammonium ions in the resulting supernatant were determined using the Nesslerization method. The CEC was then calculated and denoted as meq per gram of adsorbents.

\subsection{Batch experiments}

All batch experiments were implemented in $100 \mathrm{~mL}$ stoppered conical flasks containing $25 \mathrm{~mL}$ of solution on a temperature-controlled shaker with continuous stirring at $180 \mathrm{rpm}$.

\subsubsection{Batch experiments using synthetic ammonium solutions}

The stock solutions with ammonium concentration of $1000 \mathrm{mg} / \mathrm{L}$ were prepared from anhydrous $\mathrm{NH}_{4} \mathrm{Cl}$ (analytical grade), which was diluted to the desired experimental concentration by adding distilled water in the following experiments. The dilution was corrected when calculating the result based on the measured value.

The effect of contact time on ammonium removal by the synthesized zeolite was investigated under different contact times ranging from 0 to $360 \mathrm{~min}$ at $25^{\circ} \mathrm{C}$. The initial ammonium concentration and adsorbent dosage were $100 \mathrm{mg} / \mathrm{L}$ and $2 \mathrm{~g} / \mathrm{L}$, respectively. According to the results of contact time tests, the optimal contact time was fixed at $1.25 \mathrm{~h}$ for the following experiments. The time span was sufficient to reach equilibrium.

The effect of $\mathrm{pH}$ was investigated in the $\mathrm{pH}$ range from 3.0 to 12.0 at $25{ }^{\circ} \mathrm{C}$. The initial ammonium concentration and adsorbent dosage were $50 \mathrm{mg} / \mathrm{L}$ and $2 \mathrm{~g} / \mathrm{L}$, respectively. The suspensions were adjusted to the desired $\mathrm{pH}(3.0-12.0)$ by adding $1 \mathrm{~mol} / \mathrm{L}$ of $\mathrm{HCl}$ or $\mathrm{NaOH}$. The $\mathrm{pH}$ of the solution was monitored by a $\mathrm{pH}$ meter (DELTA 320).

The effect of the synthesized zeolite dosage on the ammonium removal was studied in the range of $0.5-6.0 \mathrm{~g} / \mathrm{L}$ at $25^{\circ} \mathrm{C}$. The initial ammonium concentration was $50 \mathrm{mg} / \mathrm{L}$. The $\mathrm{pH}$ of the solutions was adjusted to 8.0.

The effect of initial ammonium concentration was studied between 43 and $348 \mathrm{mg} / \mathrm{L}$ at $25^{\circ} \mathrm{C}$. The adsorbent dosage was $4 \mathrm{~g} / \mathrm{L}$. The $\mathrm{pH}$ of the solutions was adjusted to 8.0.

The effect of individual cations $\left(\mathrm{K}^{+}, \mathrm{Ca}^{2+}, \mathrm{Na}^{+}\right.$, and $\left.\mathrm{Mg}^{2+}\right)$ present in the solution on ammonium removal by the synthesized zeolite was investigated in the solutions at an ammonium concentration of $50 \mathrm{mg} / \mathrm{L}$ and individual cation concentrations in the range of $0-10 \mathrm{meq} / \mathrm{L}$ at $25^{\circ} \mathrm{C}$. The adsorbent dosage was $4 \mathrm{~g} / \mathrm{L}$. The $\mathrm{pH}$ of the solutions was adjusted to 8.0. Stock solutions with cation concentrations of $1.0 \mathrm{~g} / \mathrm{L}$ were added to the ammonium aqueous solutions to prepare working solutions. The cation stock solutions were prepared from $\mathrm{KCl}, \mathrm{CaCl}_{2}$, $\mathrm{NaCl}$, and $\mathrm{MgCl}_{2}$ of analytical grade, respectively.

The experiments with individual anions $\left(\mathrm{SO}_{4}^{2-}, \mathrm{Cl}^{-}\right.$, and $\left.\mathrm{CO}_{3}^{2-}\right)$ present in the ammonium solution were conducted using solutions prepared individually with $\mathrm{NH}_{4} \mathrm{Cl},\left(\mathrm{NH}_{4}\right)_{2} \mathrm{SO}_{4}$, and $\left(\mathrm{NH}_{4}\right)_{2} \mathrm{CO}_{3}$ (analytical grade). The ammonium concentration varied in the range from 2.56 to $25.07 \mathrm{meq} / \mathrm{L}$. The concentration of different anions which presented 
individually in the solution was equal each other under identical concentration of ammonium. The adsorbent dosage was $4 \mathrm{~g} / \mathrm{L}$. The $\mathrm{pH}$ of the solutions was adjusted to 8.0.

The kinetic process of ammonium removal was studied at $25^{\circ} \mathrm{C}$. The initial ammonium concentration and adsorbent dosage were $100 \mathrm{mg} / \mathrm{L}$ and $2 \mathrm{~g} / \mathrm{L}$, respectively. The kinetics of ammonium uptake determined by analyzing the adsorptive uptake of ammonium from aqueous solutions on the synthesized zeolite at different time intervals (0-360 min).

Adsorption isotherm tests were conducted at 25 and $35^{\circ} \mathrm{C}$, respectively. Twenty-five milliliter solutions in the range of $10-300 \mathrm{mg} \mathrm{NH}_{4}^{+}-\mathrm{N} / \mathrm{L}$ were agitated with the synthesized zeolite at a dosage of $4 \mathrm{~g} / \mathrm{L}$ and equilibrium $\mathrm{pH}$ of 8.0 .

\subsubsection{Batch experiments using wastewater from sewage treatment plant}

The wastewater sample was obtained from Tengzhou Sewage Treatment Plant in Shandong Province, China, and it was taken after passing through the last system of treatment (secondary) and before discharging into the river. The concentrations of main cations in the wastewater were determined by inductively coupled plasma optical emission spectrometer (ICP-OES, Optima 2000, PerkinElmer Co. USA). The batch experiments were conducted at $25^{\circ} \mathrm{C}$. The $\mathrm{pH}$ of the solutions was adjusted to 8.0 . The adsorbent dosages were $2-20 \mathrm{~g} / \mathrm{L}$.

After shaking, the suspensions of the above-mentioned batch experiments were filtered using $0.45 \mu \mathrm{m}$ cellulose acetate membrane, and the supernatants were determined using the Nesslerization method with a Unico spectrophotometer. The amounts of ammonium exchanged by the synthesized zeolite $\left(q_{e}(\mathrm{mg} / \mathrm{g})\right)$ and the ammonium removal percentage were calculated by Eqs. (1) and (2).

Amounts of ammonium exchanged $=\frac{C_{o}-C_{e}}{W} \times V$

Ammonium removal percentage $(\%)=\frac{C_{o}-C_{e}}{C_{o}} \times 100$

where $C_{o}$ and $C_{e}$ are the initial and equilibrium ammonium concentrations of the test solution $(\mathrm{mg} / \mathrm{L})$, respectively, $V$ is the test solution volume (L), and $W$ is the amount of adsorbent (g).

All the above experiments were duplicated to ensure reproducibility and the average values were used for analysis.

\subsection{Adsorbent regeneration}

The $\mathrm{NaCl}$ solution $(1 \mathrm{~mol} / \mathrm{L})$ was used for regeneration. Twenty five milliliters of the $\mathrm{NaCl}$ solution was mixed thrice with $2 \mathrm{~g}$ of ammonium-saturated zeolite. The mixture was stirred at $180 \mathrm{rpm}$ at $25^{\circ} \mathrm{C}$ for $1.25 \mathrm{~h}$. The solid residues were then washed with $25 \mathrm{~mL}$ of distilled water for $10 \mathrm{~min}$. The obtained sample was dried at $100{ }^{\circ} \mathrm{C}$ for $12 \mathrm{~h}$ and then sieved through a 100 mesh for further work. To evaluate the performance of the regenerated zeolite in ammonium removal, the effects of $\mathrm{pH}(3.0-12.0)$ and adsorbent dosage (0.5-20.0 g/L) were investigated by batch experiments. The obtained results were compared to those obtained from original zeolite.

\section{Results and discussion}

\subsection{Characterization of fly ash and its synthesized zeolite}

The XRD patterns of both fly ash and its synthesized zeolite are shown in Fig. 1. The XRD pattern of fly ash showed the presence of quartz and mullite. In the XRD pattern of the synthesized zeolite, the quartz disappeared, while a few mullites still showing there. The major crystalline phase of the synthesized zeolite was identified as zeolite X (faujasite), with small amounts of zeolite A, zeolite P and hydroxysodalite. Fly ash was converted into high-crystalline zeolite after fusion, which was proven by highly intense and narrow peaks without elevated baseline.

Morphological analyses of fly ash and its synthesized zeolite were carried out using SEM. The results are shown in Fig. 2. SEM observations of fly ash showed the presence of micro-particles in the shape of smooth balls (Fig. 2a). After fusion, the spheres were deformed, and the smooth surfaces changed into various crystal shapes (Fig. 2b). The cubic, octahedral and round crystals corresponded to zeolite A, zeolite X and zeolite $\mathrm{P}$, respectively, which also confirmed by the XRD data in Fig. 1.

The obtained values of CEC and SSA of fly ash were $0.033 \mathrm{meq} / \mathrm{g}$ and $3.147 \mathrm{~m}^{2} / \mathrm{g}$, respectively, while those of the synthesized zeolite were $2.79 \mathrm{meq} / \mathrm{g}$ and $27.015 \mathrm{~m}^{2} / \mathrm{g}$, respectively. This indicates that the CEC and SSA increased remarkably following the conversion of fly ash into zeolite. A comparison of the CECs of various zeolites is shown in Table 2. Compared to natural clinoptilolites, which are considered as the most suitable materials for ammonium removal in previous studies, the synthesized zeolite had a higher CEC. This may be because faujasite has a larger specific surface area and pore size than clinoptilolite [23]. In comparison to zeolite synthesized using the hydrothermal method, the zeolite synthesized using the fusion method also had a higher CEC. This may be caused by the formation of high-purity zeolite, as the ammonium uptake capacity depends on the zeolite content of the synthesized material [20]. Due to the different methods and experimental conditions used in the CEC measurement, only one comparison for the various natural and synthesized zeolites was possible, but it was still obvious that the zeolite synthesized from fly ash using the fusion method had high potential for removing ammonium from aqueous solutions.

\subsection{Effect of contact time}

Before performing the batch uptake equilibrium experiments, it was necessary to determine the contact time required for adsorption equilibrium. Fig. 3 shows the ammonium uptake by the synthesized zeolite as a function of contact time at $25^{\circ} \mathrm{C}$. The results reveal that the removal of ammonium by the synthesized zeolite was a very rapid process and final ammonium uptake was almost complete within the first $10 \mathrm{~min}$ of the reaction. Between 10 and $40 \mathrm{~min}$ of uptake, fluctuations could be observed. Sixty minutes after initial reaction, uptake nearly reached equilibrium, and the uptake amount of ammonium became almost stable. The fast ammonium removal rate at the initial stage of uptake was due to the fact that, initially, all adsorbent sites were vacant and the solute concentration gradient was high. Previous studies also found that ammonium uptake by zeolite is a fast process, and uptake equilibrium is achieved at even shorter time periods of 10 and $15 \mathrm{~min}$ [10]. To reach uptake equilibrium, the contact time was fixed at $1.25 \mathrm{~h}$ for the following batch experiments.

\subsection{Effect of $p H$}

pH has a significant effect on ammonium removal by zeolite, since it can affect not only the characteristics of the ammonium ion, but also the zeolite itself [27]. Ammonium removal by the synthesized zeolite was investigated at $\mathrm{pH}$ values ranging from 3.0 to 12.0. The results in Fig. 4 show that as the $\mathrm{pH}$ of the solution increased from 3.0 to 8.0 , the ammonium uptake amount increased from 2.12 to $15.84 \mathrm{mg} / \mathrm{g}$, and reached the maximum amount when the $\mathrm{pH}$ was 8.0. Afterwards, it decreased with increasing $\mathrm{pH}$, and reached the minimum amount of $1.64 \mathrm{mg} / \mathrm{g}$ at $\mathrm{pH}$ 12.0. Therefore, for ammonium uptake by the synthesized zeolite, the optimal pH was 8.0.

This behavior can be explained by the fact that at $\mathrm{pH}$ values above 8.0, part of the synthesized zeolite is dissolved. As well, part of the $\mathrm{NH}_{4}^{+}$is converted into $\mathrm{NH}_{3}$. $\mathrm{NH}_{3}$ cannot be removed by the synthesized zeolite because only the ionized form can be removed 


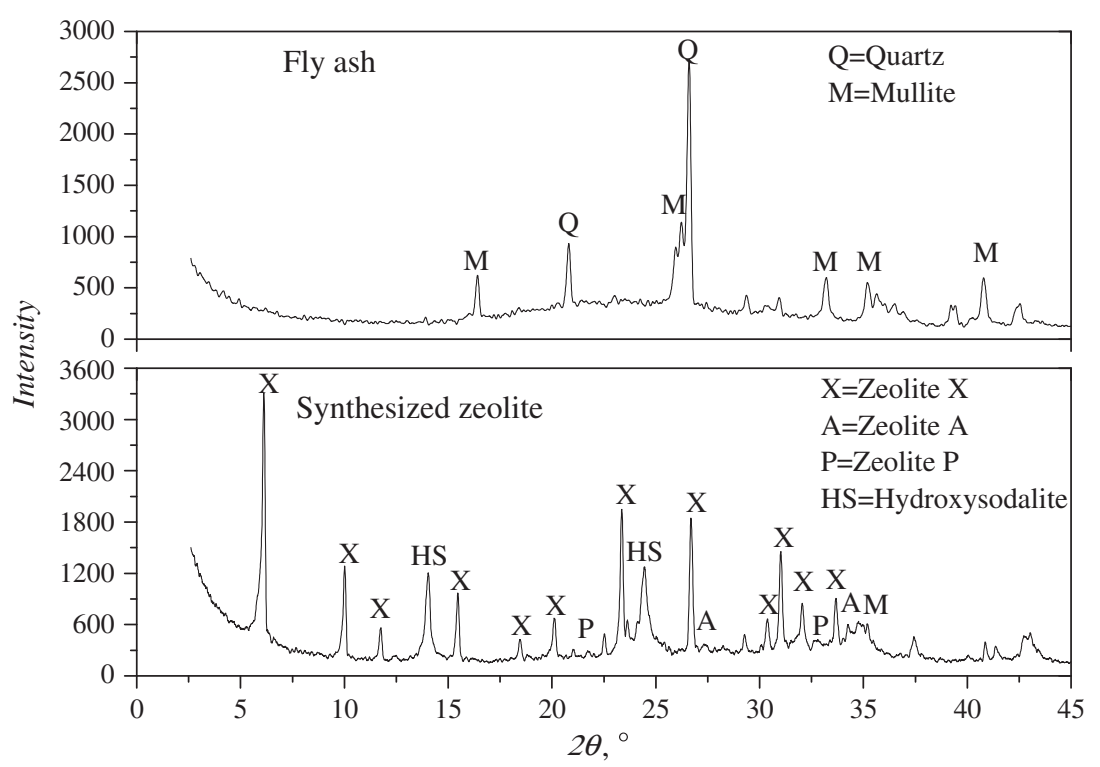

Fig. 1. XRD patterns of fly ash and its synthesized zeolite.

from solution by ion exchange. At $\mathrm{pH}$ values below 8 , the ammoniacal nitrogen is mostly present in the ionized form, and the ammonium ion concentration in the solution rises when the $\mathrm{pH}$ decreases. However, the results show a decline in removal capacity. This is probably because the hydrogen ion concentration also rises with decreasing $\mathrm{pH}$, intensifying competition for exchange sites [17,27]. Moreover, zeolite crystals begin to collapse or dissolve with decreasing $\mathrm{pH}$ in aqueous solutions, particularly when the $\mathrm{pH}$ is below 4.0 [16].

\subsection{Effect of adsorbent dosage}

The effect of the quantity of synthesized zeolite used for ammonium removal was tested to determine the balance between the ammonium uptake capacity and removal efficiency resulting in optimum adsorbent dosage. The plots of the relative uptake amount and removal efficiency of ammonium versus the adsorbent dosage are shown in Fig. 5. The results show that the removal efficiency of

(a) Fly ash
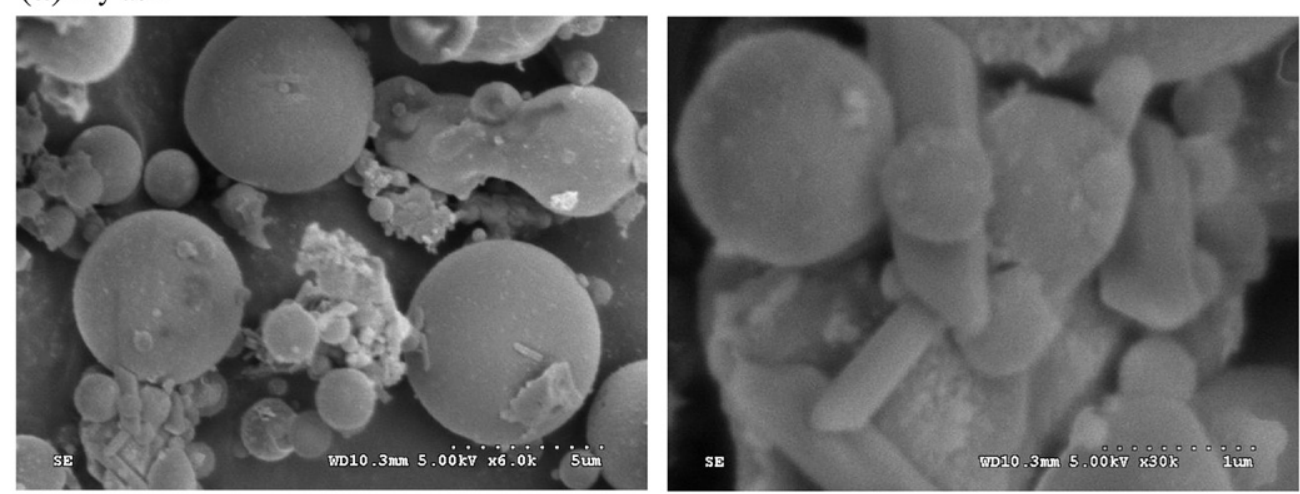

(b) Zeolite synthesized from fly ash
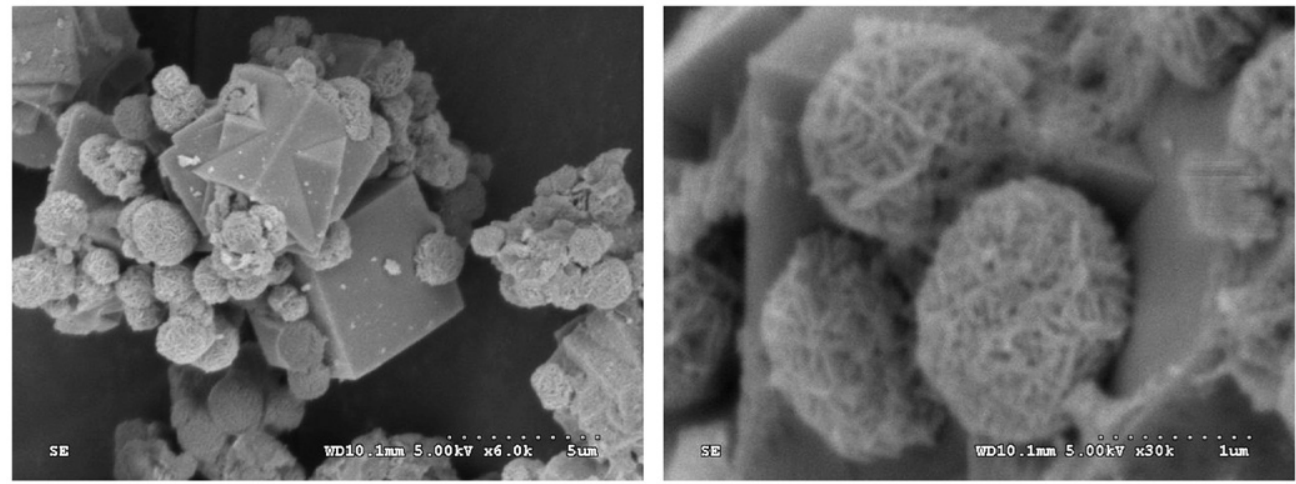

Fig. 2. SEM images of fly ash and its synthesized zeolite. 
Table 2

Comparison of CEC of natural zeolites and synthesized zeolites from fly ash.

\begin{tabular}{lll}
\hline Adsorbent & CEC (meq/g) & Reference \\
\hline Natural Turkish clinoptilolite & $0.95-1.4$ & {$[10]$} \\
Natural Croatia clinoptilolite & 1.45 & {$[25]$} \\
Natural Turkish zeolite & $1.17-2.1$ & {$[26]$} \\
Zeolite synthesized using hydrothermal method & $0.9-1.15$ & {$[15]$} \\
Zeolite synthesized using hydrothermal method & $0.88-2.13$ & {$[17]$} \\
Zeolite synthesized using hydrothermal method & 1.0 & {$[20]$} \\
Zeolite synthesized using hydrothermal method & 1.08 & {$[24]$} \\
Zeolite synthesized using fusion method & 2.50 & {$[20]$} \\
Zeolite synthesized using fusion method & 2.79 & This work \\
\hline
\end{tabular}

ammonium by the synthesized zeolite increased from $33.6 \%$ to $73.1 \%$ when the amount of adsorbent was increased from 0.5 to $6.0 \mathrm{~g} / \mathrm{L}$. A plateau occurred at the adsorbent dosage of $4.0 \mathrm{~g} / \mathrm{L}$, which may be attributed to the formation of aggregates at higher solid/liquid ratios or precipitation of particles. The ammonium uptake capacity decreased from 35.4 to $6.8 \mathrm{mg} / \mathrm{g}$ following the increase of adsorbent dosage from 0.5 to $6.0 \mathrm{~g} / \mathrm{L}$. The increase in ammonium removal percentage with the increase of the amount of synthesized zeolite can be attributed to the increase in surface area and exchange sites. The decrease in uptake capacity may be due to the decrease in the ammonium concentration gradient per unit mass of adsorbent with the increase in amount of synthesized zeolite. The driving force generated from the concentration gradient thus decreased as well. Therefore, less ammonium ions diffused though the liquid film and intra-particle channels to the exchangeable sites of the synthesized zeolite, and more sites remain unexchanged. Another reason for this may be due to the particle interaction, such as aggregation, that resulted from high sorbent concentration. Such aggregation would lead to a decrease in total surface area of the sorbent and an increase in diffusional path length. Particle interaction may also desorb some of the sorbate that is only loosely and reversibly bound to the sorbent surface. For a synthesized zeolite dosage of $1.24 \mathrm{~g} / \mathrm{L}$, the optimum values for both ammonium removal efficiency and uptake capacity were found to be $48.02 \%$ and $23.89 \mathrm{mg} / \mathrm{g}$, respectively.

\subsection{Effect of initial ammonium concentration}

To optimize removal conditions, ammonium uptake by the synthesized zeolite was studied under different initial ammonium concentrations, ranging from $43-348 \mathrm{mg} / \mathrm{L}$. The results in Fig. 6 show that the initial ammonium concentration had a significant influence on both the uptake amount and removal efficiency of ammonium. With the increase in initial ammonium concentration from 43 to $348 \mathrm{mg} / \mathrm{L}$, the ammonium removal efficiency decreased from $66.3 \%$ to $28.3 \%$. With the increase in initial ammonium concentration, the ammonium uptake capacity of the synthesized zeolite increased,

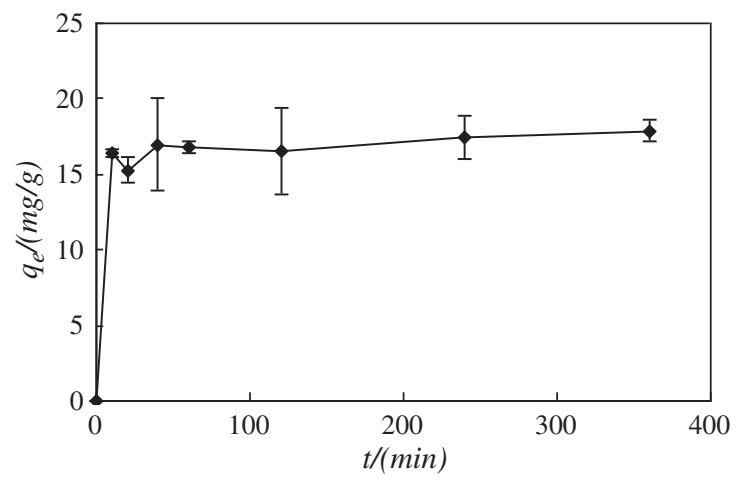

Fig. 3. Effect of contact time on ammonium removal by the synthesized zeolite $\left(\mathrm{C}_{0}=100 \mathrm{mg} \mathrm{NH} \mathrm{H}_{4}^{+}-\mathrm{N} / \mathrm{L} ;\right.$ Adsorbent dose $\left.=2 \mathrm{~g} / \mathrm{L} ; \mathrm{T}=25^{\circ} \mathrm{C}\right)$.

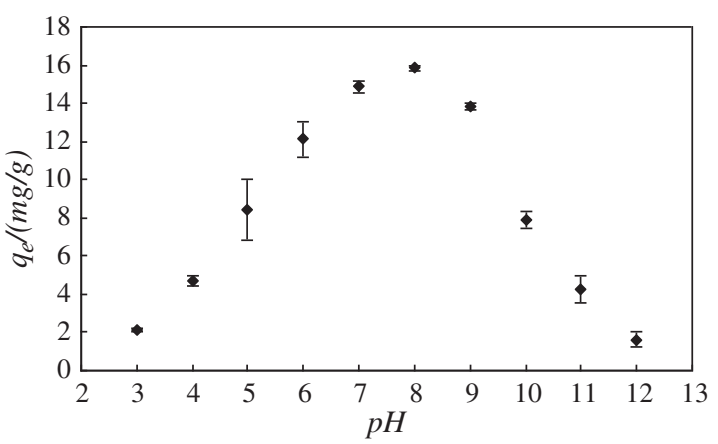

Fig. 4. Effect of $\mathrm{pH}$ on ammonium removal by the synthesized zeolite $\left(\mathrm{C}_{0}=50 \mathrm{mg} \mathrm{NH}_{4}^{+}\right.$$\mathrm{N} / \mathrm{L}$; Adsorbent dosage $=2 \mathrm{~g} / \mathrm{L} ; \mathrm{T}=25^{\circ} \mathrm{C}$ ).

reaching the maximum value at $27.26 \mathrm{mg} / \mathrm{g}$ when the initial ammonium concentration was $348 \mathrm{mg} / \mathrm{L}$. The decrease in the removal efficiency of ammonium can be explained by the fact that all adsorbents have limited exchange sites. Uptake becomes restricted when these sites are saturated. The increase in uptake capacity is the result of the increase in the driving force generated from the concentration gradient, as the concentration gradient and its derived driving force increases with increasing initial ammonium concentration. At the initial ammonium concentration of $152.6 \mathrm{mg} / \mathrm{L}$, the optimum values for both ammonium removal efficiency and uptake capacity were found to be $47.69 \%$ and $17.77 \mathrm{mg} / \mathrm{g}$, respectively.

\subsection{Effect of the individual presence of other cations}

Real municipal and industrial wastewaters are complex solutions. Other cations, such as $\mathrm{K}^{+}, \mathrm{Na}^{+}, \mathrm{Ca}^{2+}$ and $\mathrm{Mg}^{2+}$, generally coexist with the ammonium ion. The influence of the existence of these cations on ammonium removal by the synthesized zeolite was studied, and the results are shown in Fig. 7. The individual presence of other metal ions significantly reduced the removal efficiency of ammonium. With increasing initial cation concentration, ammonium removal efficiency decreased. When the concentrations of $\mathrm{Ca}^{2+}, \mathrm{Mg}^{2+}, \mathrm{Na}^{+}$and $\mathrm{K}^{+}$were increased from 0 to $10 \mathrm{meq} / \mathrm{L}$, the removal efficiency of ammonium decreased from $69.91 \%$ to $44.91 \%, 64.35 \%, 53.77 \%$, and $41.54 \%$, respectively. Given identical concentrations of metal cations, reduction followed the order of $\mathrm{K}^{+}>\mathrm{Ca}^{2+}>\mathrm{Na}^{+}>\mathrm{Mg}^{2+}$. This indicates that the selectivity order of ammonium over other cations on the synthesized zeolite was $\mathrm{K}^{+}>\mathrm{Ca}^{2+}>\mathrm{Na}^{+}>\mathrm{Mg}^{2+}$.

Different results for the selectivity of the natural and synthesized zeolite toward $\mathrm{Ca}^{2+}, \mathrm{K}^{+}, \mathrm{Na}^{+}$, and $\mathrm{Mg}^{2+}$ were obtained in previous studies. Huang et al. [11] and Lei et al. [28] provided an order of preference of $\mathrm{Na}^{+}>\mathrm{K}^{+}>\mathrm{Ca}^{2+}>\mathrm{Mg}^{2+}$. However, Weatherley and Miladinovic [29]

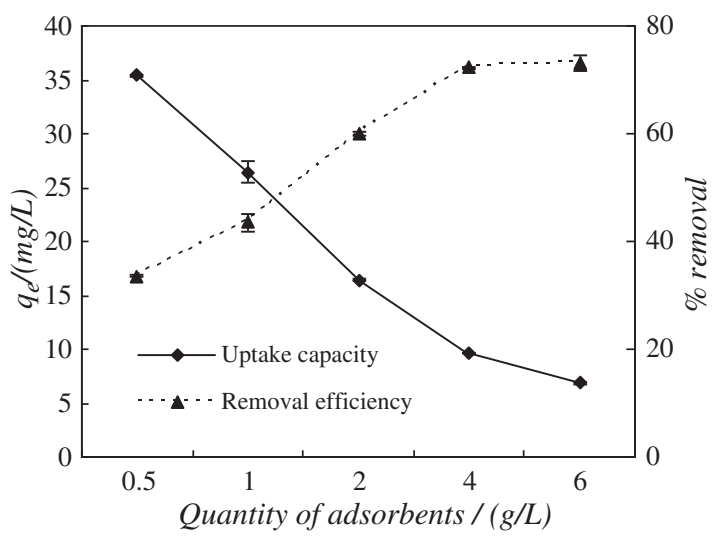

Fig. 5. Effect of the synthesized zeolite loadings on the ammonium removal efficiency and uptake capacity $\left(\mathrm{C}_{0}=50 \mathrm{mg} \mathrm{NH} \mathrm{N}_{4}^{+}-\mathrm{N} / \mathrm{L} ; \mathrm{pH}=8.0 ; \mathrm{T}=25^{\circ} \mathrm{C}\right)$. 


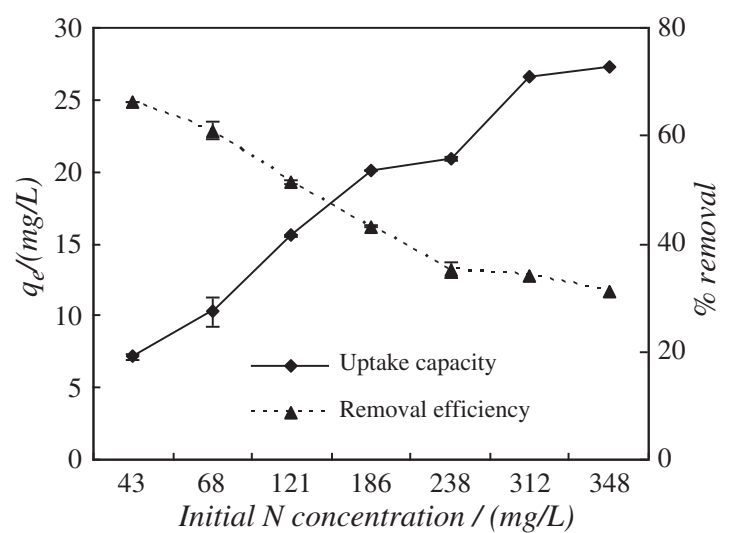

Fig. 6. Effect of initial ammonium concentration on the ammonium removal efficiency and uptake capacity by the synthesized zeolite (Adsorbent dosage $=4 \mathrm{~g} / \mathrm{L} ; \mathrm{pH}=8.0$; $\left.\mathrm{T}=25^{\circ} \mathrm{C}\right)$.

suggested $\mathrm{Ca}^{2+}>\mathrm{K}^{+}>\mathrm{Mg}^{2+}$. Wang et al. [30] provided different orders for natural clinoptilolite and its modified zeolite; the natural clinoptilolite followed the order: $\mathrm{K}^{+}>\mathrm{Ca}^{2+}>\mathrm{Mg}^{2+}$, whereas its modified zeolite followed the order $\mathrm{Mg}^{2+}>\mathrm{Ca}^{2+}>\mathrm{K}^{+}$. These results confirm that different zeolites have different characters and thus different cation selectivities.

\subsection{The effect of anions}

Previous studies have shown that the presence of different anions with the ammonium ion can also affect the ammonium uptake capacity of zeolite [11]. The influence of different anions on ammonium uptake by the synthesized zeolite in this study as a function of different initial ammonium concentrations is presented in Fig. 8. The results show that the removal efficiency of ammonium decreased when the initial ammonium concentration increased, similar to observations involving cations. When the concentration of ammonium was less than $7.14 \mathrm{meq} /$ $\mathrm{L}$, the removal efficiency of ammonium in the solution with each individual anion remained almost the same. Afterwards, the removal efficiency differed for each anion. When the initial ammonium concentration increased from $2.56 \mathrm{meq} / \mathrm{L}$ to $25.07 \mathrm{meq} / \mathrm{L}$ with $\mathrm{CO}_{3}^{2-}$, $\mathrm{Cl}^{-}$, and $\mathrm{SO}_{4}^{2-}$ individually present in the solution, the ammonium removal efficiency decreased from about $68.7 \%$ to $26.5 \%, 28.3 \%$, and $38.4 \%$, respectively. This suggests that the order of anion effects on ammonium removal by the synthesized zeolite was $\mathrm{CO}_{3}^{2-}>\mathrm{Cl}^{-}>\mathrm{SO}_{4}^{2-}$, consistent with reports from other authors [11].

\subsection{Kinetics}

The study of uptake kinetics is necessary as it provides valuable insights into both the reaction pathway and the rate-controlling

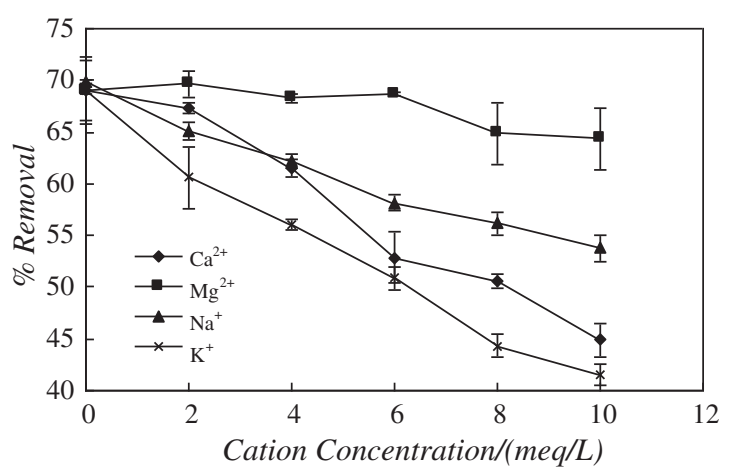

Fig. 7. Effects of the individual presence of other cations on the removal of ammonium ions (Adsorbent dose $=4 \mathrm{~g} / \mathrm{L} ; \mathrm{pH}=8 ; \mathrm{T}=25^{\circ} \mathrm{C}$ ).

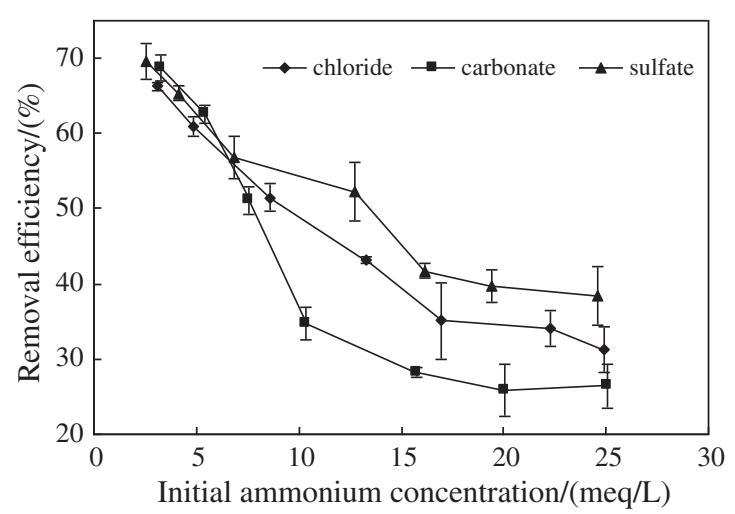

Fig. 8. Effects of the individual presence of anions on the removal of ammonium by the synthesized zeolite (Adsorbent dose $=4 \mathrm{~g} / \mathrm{L} ; \mathrm{pH}=8 ; \mathrm{T}=25{ }^{\circ} \mathrm{C}$ ).

mechanism of exchange reactions. It is also required for selecting optimum operating conditions for full-scale batch processes [31]. To understand the exchange process of ammonium by the synthesized zeolite, Lagergren first-order, Ho' pseudo-second-order, and intraparticle diffusion kinetic models were employed to test the experimental data [32-34]. The Lagergren first-order, Ho' pseudo-secondorder and intraparticle diffusion kinetic models are respectively described in the following equations:

$$
\ln \left(q_{e}-q_{t}\right)=\ln q_{e}-k_{1} t
$$

$\frac{t}{q_{t}}=\frac{1}{k_{2} q_{e}^{2}}+\frac{t}{q_{e}}$

$q_{t}=k_{i p d} t^{0.5}+C$

where $q_{e}$ and $q_{t}$ are the amounts of adsorbate adsorbed on the adsorbents ( $\left.\mathrm{mg} \mathrm{g}^{-1}\right)$ at equilibrium and at time $t$, respectively. The values $k_{1}\left(\min ^{-1}\right)$ and $k_{2}\left(\mathrm{~g} \mathrm{mg}^{-1} \mathrm{~min}^{-1}\right)$ are the rate constants of the first- and second-order models, respectively, and $k_{i p d}$ is the diffusion coefficient of intraparticle diffusion model. $C$ is the intercept.

The results in Fig. 9a and b show that the coefficient of determination $\left(\mathrm{R}^{2}=0.9994\right)$ for the Ho' pseudo-second-order model was much higher than that obtained using the Lagergren first-order model $\left(\mathrm{R}^{2}=0.464\right)$. Thus, the Ho' pseudo-second-order model explains the kinetic process better, suggesting that chemisorption, i.e., the process of ion exchange, is the rate-controlling step for the uptake process of ammonium by the synthesized zeolite. The predicted value of $q_{e}$ using a pseudo-second-order model was $17.92 \mathrm{mg} /$ $\mathrm{g}$, which was very close to the experimental data $(20.14 \mathrm{mg} / \mathrm{g})$. The obtained rate constant $k_{2}$ was $1.44 \times 10^{-2} \mathrm{~g} \cdot \mathrm{mg}^{-1} \mathrm{~min}^{-1}$.

The intraparticle diffusion model as fitted with the experimental data is presented in Fig. $9 \mathrm{c}$ as the plot of $q_{t}$ versus $t^{0.5}$; the values of $K_{i p d}$ and the correlation coefficients are also given. The results show that ammonium uptake by the synthesized zeolite involved two stages: surface sorption and intraparticle diffusion. The first linear portion is attributed to the boundary layer diffusion effect and the final linear portions are attributed to the intraparticle diffusion effect, which was consistent with the results of previous studies [10]. However, the correlation coefficients of the intraparticle model were lower than that of pseudo-second-order model. The curves of the plots did not pass through the origin, indicating that intraparticle diffusion was involved in the uptake process but was not the rate-controlling step.

\subsection{Adsorption isotherm}

Adsorption isotherms are important for revealing how the ammonium ion comes into contact with zeolite and are useful for 
(a) Lagergren first-order model



(b) Ho'pseudo-second-order model

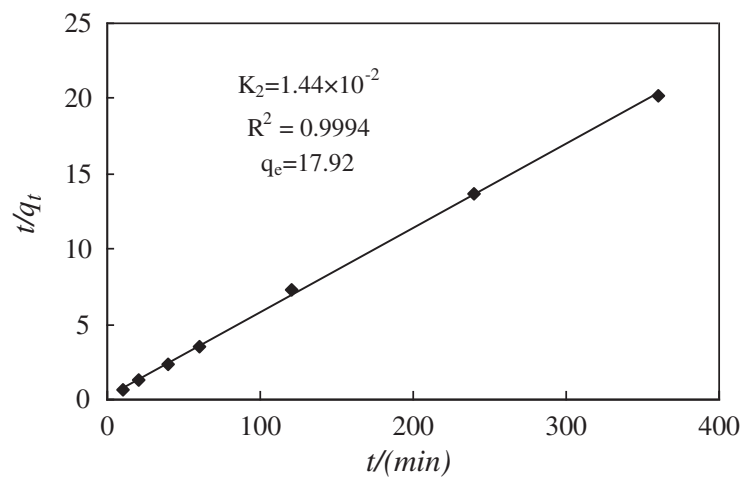

(c) Intraparticle diffusion kinetic model

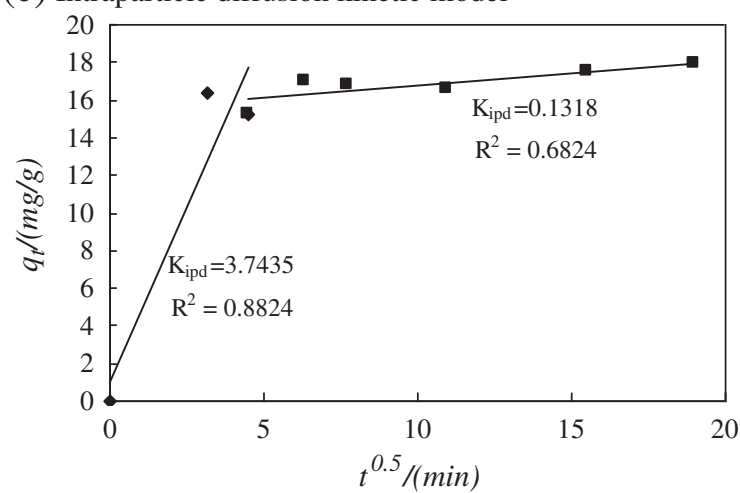

Fig. 9. Plots of kinetics of ammonium removal by the synthesized zeolite $\left(C_{0}=100 \mathrm{mg}\right.$ $\mathrm{NH}_{4}^{+}-\mathrm{N} / \mathrm{L} ;$ Adsorbent dose $=2 \mathrm{~g} / \mathrm{L} ; \mathrm{T}=25^{\circ} \mathrm{C}$ ).

designing fixed-bed uptake columns and characterizing the shape of breakthrough curves. Five adsorption isotherms, the Langmuir, Freundlich, Koble-Corrigan, Tempkin, and Dubinin-Radushkevich equations, which are available in the literature, were fitted with the experimental data to find the most suitable model [35-39].

\subsubsection{Langmuir isotherm}

The Langmuir isotherm assumes that adsorption happens at specific homogeneous sites within the adsorbent, and there is no interaction between the adsorbate molecules. The isotherm equation is written in the following form:

$\frac{C_{e}}{q_{e}}=\frac{1}{b Q_{m}}+\left(\frac{1}{Q_{m}}\right) C_{e}$

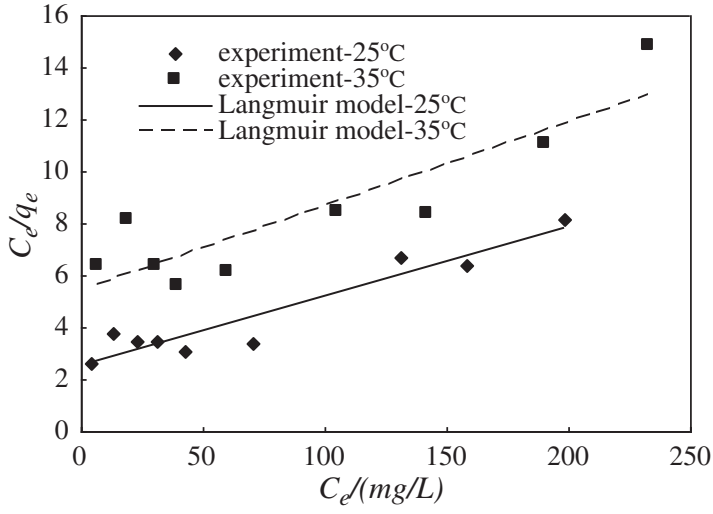

Fig. 10. Langmuir isotherm plots for the uptake of ammonium on the synthesized zeolite.

where $b$ is the adsorption equilibrium constant $(\mathrm{L} / \mathrm{mg})$, which is related to the free energy of adsorption, $Q_{m}$ is the maximum monolayer adsorption capacity, and $Q_{\mathrm{e}}$ is the amount adsorbed on a unit mass of the adsorbent $(\mathrm{mg} / \mathrm{g})$ when the equilibrium concentration is $C_{\mathrm{e}}(\mathrm{mg} / \mathrm{L})$.

Further analysis of the Langmuir equation can be realized on the basis of a dimensionless equilibrium parameter, $R_{L}$, given by $R_{L}=\frac{1}{1+b C_{0}}$ [40]. A value of $R_{L}$ between 0 and 1 represents favorable adsorption, while $R_{L}>1$ represents unfavorable adsorption, $R_{L}=1$ represents linear adsorption, and $R_{L}=0$ represents irreversible adsorption.

The isotherm experimental data, which were collected at different initial ammonium concentrations and temperatures, were plotted between $C_{e} / q_{\mathrm{e}}$ versus $C_{e}$ (Fig. 10). The values of $Q_{m}$ and $b$ were calculated from the slope and the intercept of the plots, respectively, and are given in Table 3. The Langmuir constant $Q_{m}$ at 25 and $35^{\circ} \mathrm{C}$ was obtained as 37.45 and $30.86 \mathrm{mg} / \mathrm{g}$, respectively, which was higher than the experimental results $\left(24.3 \mathrm{mg} / \mathrm{g}\right.$ at $25^{\circ} \mathrm{C}$ and $15.7 \mathrm{mg} / \mathrm{g}$ at $\left.35^{\circ} \mathrm{C}\right)$. The Langmuir constant $b$ was found to be $0.0105 \mathrm{~L} / \mathrm{mg}\left(25^{\circ} \mathrm{C}\right)$ and $0.00599 \mathrm{~L} / \mathrm{mg}\left(35^{\circ} \mathrm{C}\right)$, decreasing with increasing temperature. This indicates that ammonium uptake is an exothermic reaction. The low values of $b$ indicate the high affinity between ammonium and the synthesized zeolite. The obtained values of coefficients of determination at $25^{\circ} \mathrm{C}$ and $35^{\circ} \mathrm{C}$ were 0.91 and 0.79 , respectively. The dimensionless parameter $\mathrm{R}_{\mathrm{L}}$ was in the range of 0.24 and 0.94 $\left(0<R_{L}<1\right)$, suggesting that the uptake process was a favorable one.

Table 3

Isotherm constants and regression data of five adsorption isotherms for uptake of ammonium on the synthesized zeolite at different temperatures (adsorbent dose $=4 \mathrm{~g}$ / $\mathrm{L} ; \mathrm{pH}=8.0$ ).

\begin{tabular}{|c|c|c|}
\hline \multirow[t]{2}{*}{ Adsorption isotherm } & \multicolumn{2}{|l|}{ Temperature } \\
\hline & $25\left({ }^{\circ} \mathrm{C}\right)$ & $35\left({ }^{\circ} \mathrm{C}\right)$ \\
\hline Langmuir & $\begin{aligned} Q_{m} & =37.45 \\
b & =0.0104 \\
R^{2} & =0.9055\end{aligned}$ & $\begin{aligned} Q_{m} & =30.86 \\
b & =0.00599 \\
R^{2} & =0.7931\end{aligned}$ \\
\hline Freundlich & $\begin{array}{l}K_{F}=0.6375 \\
n_{F}=0.7364 \\
R^{2}=0.9479\end{array}$ & $\begin{array}{l}K_{F}=0.2607 \\
n_{F}=0.8177 \\
R^{2}=0.9485\end{array}$ \\
\hline Koble-Corrigan & $\begin{aligned} a & =0.0216 \\
b & =8.72 \times 10^{-4} \\
n & =1.937 \\
R^{2} & =0.9602\end{aligned}$ & $\begin{aligned} a & =0.0202 \\
b & =0.0011 \\
n & =1.699 \\
R^{2} & =0.9701\end{aligned}$ \\
\hline Tempkin & $\begin{aligned} A_{T} & =0.184 \\
b_{T} & =370.279 \\
R^{2} & =0.91\end{aligned}$ & $\begin{aligned} A_{T} & =0.121 \\
b_{T} & =505.93 \\
R^{2} & =0.9264\end{aligned}$ \\
\hline Dubinin Radushkevich & $\begin{aligned} Q_{m} & =13.71 \\
K & =7.43 \\
R^{2} & =0.626\end{aligned}$ & $\begin{aligned} Q_{m} & =9.81 \\
K & =18.063 \\
R^{2} & =0.662\end{aligned}$ \\
\hline
\end{tabular}




\subsubsection{Freundlich isotherm}

The Freundlich isotherm is an empirical equation used to describe heterogeneous systems. It is expressed in the following form:

$\log q_{e}=\log K_{f}+n_{f} \log C_{e}$

where $K_{f}$ and $n_{f}$ are the Freundlich constants, indicating the relative adsorption capacity and the adsorption intensity, respectively. $C_{e}$ and $q_{e}$ are similar to those in the Langmuir isotherm model. The $n_{f}$ should be in the range of $0.1-1$ for beneficial adsorption.

Freundlich isothermal plots are presented in Fig. 11, and the Freundlich constants are listed in Table 3 . The obtained $K_{f}$ was in the range of $0.64-0.26$, and decreased with the increase of temperature. These results again confirm the exothermic nature of ammonium uptake by the synthesized zeolite. The $n_{f}$ was $0.74-0.82$ and in the range of beneficial adsorption, which was consistent with the results obtained by the Langmuir isotherm. The coefficient of determination $\left(R^{2}=0.95\right)$ was higher than that of the Langmuir isotherm model, indicating that the Freundlich isotherm model fits the experimental data better compared to the Langmuir model.

\subsubsection{Koble-Corrigan model}

The Koble-Corrigan model is an isotherm that combines the Langmuir and Freundlich isotherm models. Its form is given below:

$q_{e}=\frac{a C_{e}^{n}}{1+b C_{e}^{n}}$

where, $a, b$, and $n$ are the Koble-Corrigan parameters. $C_{e}$ and $q_{e}$ are the same as those in the Langmuir isotherm model.

The experimental equilibrium data and the predicted equilibrium data obtained using the Koble-Corrigan model are plotted in Fig. 12. The obtained values of the constants, $a, b$, and $n$ are listed in Table 3 . The coefficients of determination for the Koble-Corrigan isotherm model at 25 and $35^{\circ} \mathrm{C}$ were 0.96 and 0.97 , respectively. Compared to the Langmuir and Freundlich models, the Koble-Corrigan isotherm model fits better the experimental equilibrium data. This indicates that a combination of heterogeneous and homogeneous uptake occurred for ammonium uptake by the synthesized zeolite. Comparing the coefficients of determination of the Langmuir and Freundlich models, we infer that heterogeneous uptake was the main mechanism of the ammonium adsorption process.

\subsubsection{Tempkin isotherm}

The Tempkin isotherm model takes into account adsorbentadsorbate interactions. It assumes that the heat of adsorption decreases linearly with the coverage due to adsorbent-adsorbate interaction. The form of the Tempkin equation is given as:

$q_{e}=B_{T} \ln A_{T}+B_{T} \ln C_{e}$

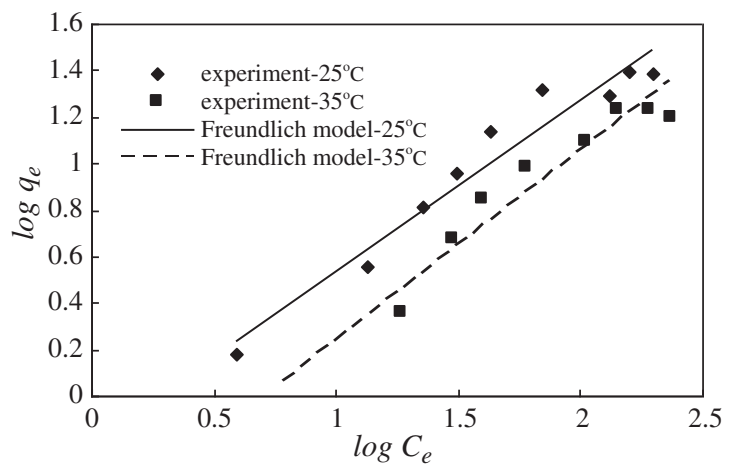

Fig. 11. Freundlich isotherm plots for the uptake of ammonium on the synthesized zeolite.

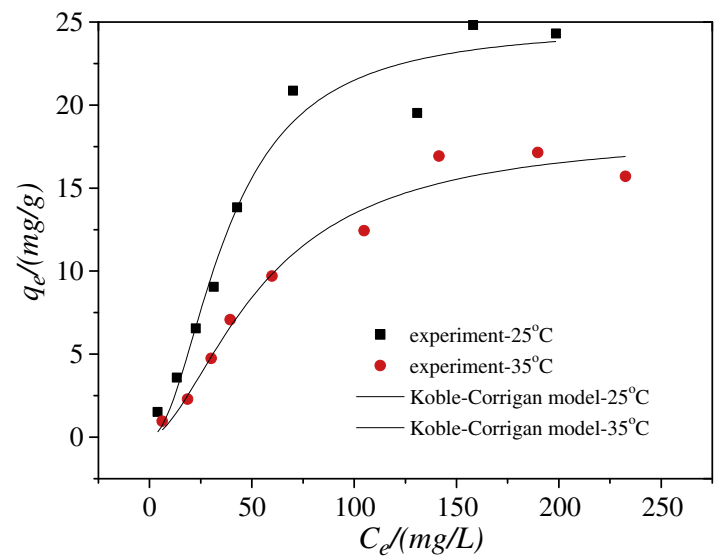

Fig. 12. Koble Corrigan isotherm plots for the uptake of ammonium on the synthesized zeolite.

where $B_{T}=\frac{R T}{b_{T}}$. The constant $b_{T}$ is related to the heat of adsorption, $A_{T}$ is the equilibrium binding constant $(\mathrm{L} / \mathrm{min})$ corresponding to the maximum binding energy, $T$ is the absolute temperature in $K$ and $R$ is the universal gas constant $\left(8.314 \mathrm{~J} \cdot \mathrm{mol}^{-1} \mathrm{~K}^{-1}\right)$, and $C_{e}$ and $q_{e}$ are the same as those in the Langmuir isotherm model.

The plots of $q_{e}$ versus $\ln C_{e}$ at different temperatures are shown in Fig. 13. Tempkin constants were calculated from the slope and intercept of Fig. 13 and are given in Table 3 . The constant $A_{T}$ was 0.184 and $0.121 \mathrm{~L} / \mathrm{min}$ at 25 and $35{ }^{\circ} \mathrm{C}$, respectively, while the $b_{T}$ was 370.3 and 505.9 at the two temperatures. The coefficients of determination $\left(R^{2}\right)$ for Tempkin isotherm model were $0.91\left(25^{\circ} \mathrm{C}\right)$ and $0.93\left(35^{\circ} \mathrm{C}\right)$. Compared to the Langmuir isotherm model, the Tempkin isotherm model fits the experimental equilibrium data better, but it was not as good as the Freundlich and Koble-Corrigan isotherm models.

\subsubsection{Dubinin-Radushkevich (D-R) isotherm}

The $\mathrm{D}-\mathrm{R}$ isotherm is used to describe the adsorption process of microporous adsorbents, such as activated carbon. It is applied to estimate the mean free energy of adsorption $(E)$. Based on the principle of this model, if the value of $E$ is between 1 and $16 \mathrm{~kJ} \mathrm{~mol}^{-1}$, physical adsorption prevails; if the value is greater than $16 \mathrm{~kJ} \mathrm{~mol}^{-1}$, chemisorption prevails. The D-R equation is given as:

$$
\begin{aligned}
& \ln q_{e}=\ln Q_{m}-K \varepsilon^{2} \\
& \varepsilon=R T \ln \left(1+\frac{1}{C_{e}}\right)
\end{aligned}
$$

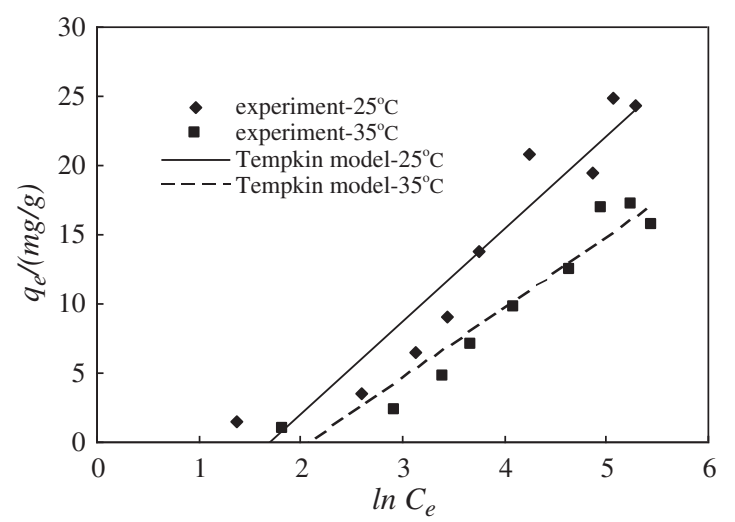

Fig. 13. Tempkin isotherm plots for the uptake of ammonium on the synthesized zeolite. 
where $K\left(\mathrm{~mol}^{2} / \mathrm{kJ}^{2}\right)$ is a constant related to the adsorption energy, $Q_{m}$ $(\mathrm{mg} / \mathrm{g})$ is the maximum adsorption capacity, and $C_{e}$ and $q_{e}$ are the same as those in the Langmuir isotherm model.

E can be calculated using Eq. (12):

$E=\frac{1}{\sqrt{2 K}}$

The plots between $\ln q_{e}$ and $\varepsilon^{2}$ at different temperatures are shown in Fig. 14. The obtained constants are listed in Table 3. The obtained $Q_{m}$ at 25 and $35^{\circ} \mathrm{C}$ was 13.71 and $9.81 \mathrm{mg} / \mathrm{g}$, respectively. The mean free energy of adsorption $E$ was 0.26 and $0.17 \mathrm{~kJ} / \mathrm{mol}$ at the two temperatures, respectively. Since these values were all smaller than $16 \mathrm{~kJ} / \mathrm{mol}$, physical uptake prevailed for the uptake of ammonium by the synthesized zeolite. The obtained coefficients of determination at 25 and $35{ }^{\circ} \mathrm{C}$ were 0.63 and 0.66 , respectively, much smaller than those obtained from the other isotherm models as given in Table 3 . This implies that the experimental equilibrium data cannot be described by the D-R model.

\subsubsection{Summary of the adsorption isotherm studies}

The above analyses showed that the Koble-Corrigan model yields a better fit than the other models. The Freundlich and Tempkin models also describe the uptake process, while the Langmuir and D-R models fail to express the equilibrium relation.

A comparison of the ammonium uptake capacities by various zeolites is shown in Table 4. It may be difficult to compare the ammonium uptake of the synthesized zeolite in our study to those found by other authors, as doing so would require that the experiments are carried out under the same experimental conditions. However, it is generally true to say that the synthesized zeolite in this study had a strong capacity for ammonium uptake. As a synthesized material from waste products, it is easily-available and high-efficient as an adsorbent for ammonium removal.

\subsection{Adsorption thermodynamics}

Based on the constant values obtained using the Langmuir isotherm model, thermodynamic parameters, i.e., enthalpy $(\Delta H)$, entropy $(\Delta S)$, and free energy $(\Delta G)$ changes were calculated using the following equations:

$$
\begin{gathered}
\ln b=\frac{\Delta S}{R}-\frac{\Delta H}{R T} \\
\Delta G=\Delta H-T \Delta S
\end{gathered}
$$

where $b$ is the Langmuir constant at $T$.

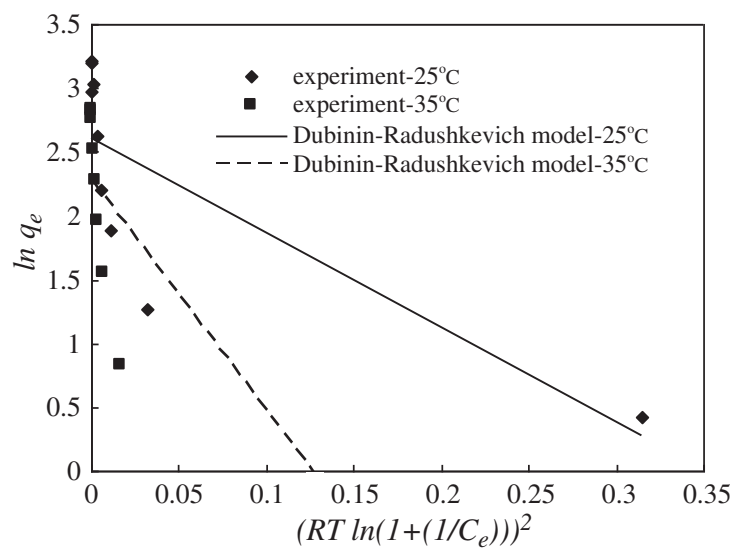

Fig. 14. D-R isotherm plots for the uptake of ammonium on the synthesized zeolite.
Table 4

Exchange capacities of ammonium by various natural and synthesized zeolites.

\begin{tabular}{lll}
\hline Adsorbent & $\begin{array}{l}\text { Exchange capacity }(\mathrm{mg} / \mathrm{g}) \\
\left(\mathrm{C}_{\mathrm{e}}=100 \mathrm{mg} \mathrm{N} / \mathrm{L}\right)\end{array}$ & Reference \\
\hline Natural Turkish clinoptilolite & $6.62\left(25^{\circ} \mathrm{C}\right), 5.50\left(40^{\circ} \mathrm{C}\right)$, & {$[10]$} \\
& $4.01\left(50^{\circ} \mathrm{C}\right)$ & \\
Mesolite & $49\left(20^{\circ} \mathrm{C}\right)$ & {$[12]$} \\
Natural Croatia clinoptilolite & $4.24\left(20^{\circ} \mathrm{C}\right)$ & {$[25]$} \\
Natural Turkish zeolite & $12.83\left(20^{\circ} \mathrm{C}\right)$ & {$[26]$} \\
New Zealand mordenite and & $6.54($ Clinoptilolite $), 12.01$ & {$[30]$} \\
$\quad$ clinoptilolite & $($ Mordenite $)$ & \\
Bigadic zeolite (Turkey) & $4.6($ Raw $), 9.7(\mathrm{Conditioned})$ & {$[41]$} \\
Zeolite synthesized from fly & $7.02\left(C_{e}=22.4 \mathrm{mg} / \mathrm{L}\right)$ & {$[15]$} \\
$\quad$ ash using hydrothermal method & & \\
Zeolite synthesized from fly & $0-14.4$ & {$[17]$} \\
$\quad$ ash using hydrothermal method & & This work \\
Zeolite synthesized from fly ash & $24.3\left(25^{\circ} \mathrm{C}\right)$ & \\
\hline
\end{tabular}

The obtained results are listed in Table 5 . The free energy changes $(\Delta G)$ obtained were -12.98 and $-11.98 \mathrm{KJ} \mathrm{mol}^{-1}$ at 25 and $35^{\circ} \mathrm{C}$, respectively. The negative values of $\Delta G$ indicate the spontaneous nature of ammonium uptake by the synthesized zeolite. The enthalpy $(\Delta H)$ was $-42.83 \mathrm{KJ} \mathrm{mol}^{-1}$, which showed the exothermic nature of uptake. This confirms the previous results in the section regarding adsorption isotherm studies. The negative value of entropy $(\Delta S=$ $-100.15 \mathrm{~J} \mathrm{~mol}^{-1} \mathrm{~K}^{-1}$ ) showed that randomness decreased the removal of ammonium by the synthesized zeolite. As the temperature increased, the decrease in ammonium uptake may also be due to the decreased rate of diffusion of ammonium, as diffusion is an exothermic process.

3.11. Comparison of the performance of the original and regenerated zeolite in ammonium uptake

To reduce treatment costs, the ability to reuse and recycle adsorbents is essential. To determine their ammonium uptake capacity, the regenerated zeolite was reloaded with known concentrations of an ammonium solution. Fig. 15 reveals ammonium removal by regenerated zeolite at different $\mathrm{pH}$ values and adsorbent dosages. As well, the obtained results were compared to those of original zeolite.

The results show that the patterns of ammonium uptake by the regenerated zeolite with different $\mathrm{pH}$ values and adsorbent dosages were similar to those of original zeolite. The maximum uptake capacity also occurred at a $\mathrm{pH}$ of 8.0, and ammonium uptake capacity also decreased with increasing regenerated zeolite dosage. Comparing the uptake capacities of the regenerated and original zeolite, we observe a slight decrease of $1.49 \mathrm{mg} / \mathrm{g}$ the ammonium uptake capacity (Fig. 15). This decrease may be due to the partial destruction of adsorbent structures during the regeneration procedure. The destruction of zeolite structures during regeneration was also found in other studies [26]. These results still show that the regenerated zeolite still had high capability for ammonium removal. Thus, the synthesized zeolite can be used to remove ammonium from wastewater.

Table 5

Thermodynamic parameters for the uptake of ammonium on the synthesized zeolite.

\begin{tabular}{lllll}
\hline Sorbent & $\Delta G\left(\mathrm{KJ} \cdot \mathrm{mol}^{-1}\right)$ & & $\begin{array}{l}\Delta H \\
\left(\mathrm{KJ} \mathrm{mol}^{-1}\right)\end{array}$ & $\begin{array}{l}\Delta S \\
\left(\mathrm{~J} \mathrm{~mol}^{-1} \mathrm{~K}^{-1}\right)\end{array}$ \\
\cline { 2 - 5 } $25{ }^{\circ} \mathrm{C}$ & $35^{\circ} \mathrm{C}$ & -11.98 & -42.83 & -100.15 \\
\hline Synthesized zeolite & -12.98 & -15 & \\
\hline
\end{tabular}


(a) Adsorbents dosage $=4 \mathrm{~g} / \mathrm{L}, C_{0}=50 \mathrm{mg} \cdot \mathrm{l}^{-1}, \mathrm{~T}=25^{\circ} \mathrm{C}$

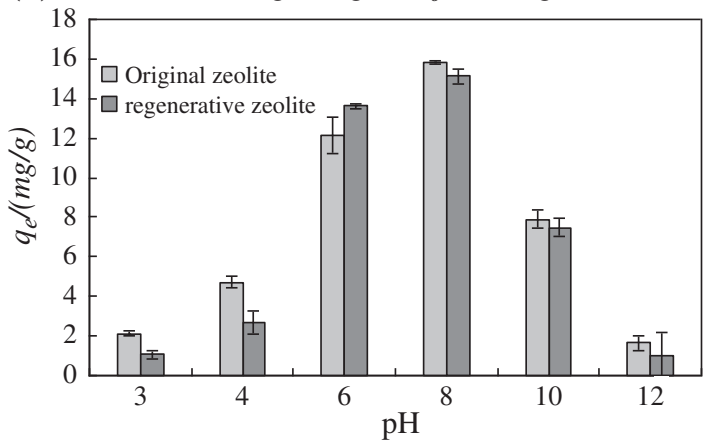

(b) $C_{0}=50 \mathrm{mg} \cdot \mathrm{l}^{-1}, \mathrm{~T}=25^{\circ} \mathrm{C}, \mathrm{pH}=8.0$

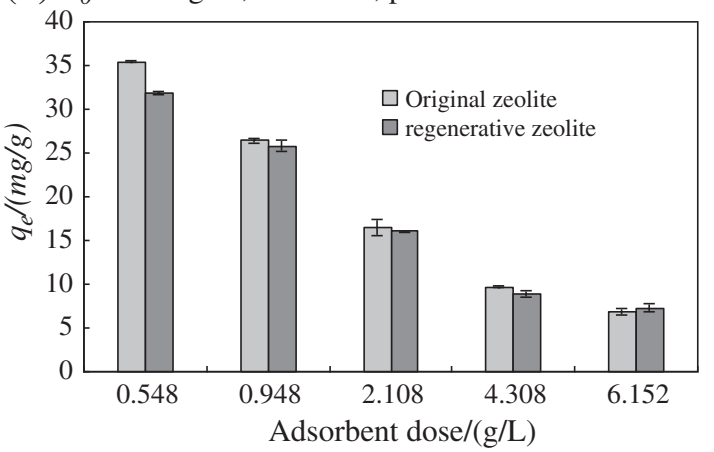

Fig. 15. Comparison of the removal performance of ammonium by original and regenerated zeolites.

\subsection{The performance of the synthesized zeolite in ammonium uptake in} wastewater from sewage treatment plant

In order to know the actual capacity of the synthesized zeolite for the ammonium removal, its performance in ammonium uptake in the wastewater after secondary treatment at Tengzhou Sewage Treatment Plant was investigated. The ammonium concentrations in equilibrium after treatment by the synthesized zeolite and percentages of ammonium removal are given for original zeolite and regenerative zeolite in Table 6 . The concentrations of $\mathrm{Na}^{+}, \mathrm{K}^{+}, \mathrm{Ca}^{2+}$, and $\mathrm{Mg}^{2+}$ in the wastewater were determined as $84.05 \mathrm{mg} / \mathrm{L}$, $19.15 \mathrm{mg} / \mathrm{L}, 70.54 \mathrm{mg} / \mathrm{L}$ and $28.08 \mathrm{mg} / \mathrm{L}$, respectively. The initial ammonium concentration was measured as $7.3 \mathrm{mg} / \mathrm{L}$, which belonged to Class II effluent according to discharge standard of pollutants for municipal wastewater treatment plant in China. The results in Table 6 showed that with the increase of the synthesized zeolite dosage from $2 \mathrm{~g} / \mathrm{L}$ to $20 \mathrm{~g} / \mathrm{L}$, the ammonium concentrations in equilibrium after treatment decreased while the percentages of ammonium removal increased. When the amounts of the synthesized zeolite added were $12 \mathrm{~g} / \mathrm{L}$ and $20 \mathrm{~g} / \mathrm{L}$, the ammonium concentrations in the wastewater basically met the Surface Water Environment Quality Standard GB3838-2002 (China) V and IV after treatment, respectively.

Although the zeolite still exhibits high ammonium uptake in the synthetic solutions after retention-regeneration process (section 3.11), the presence of $\mathrm{Na}^{+}, \mathrm{K}^{+}, \mathrm{Ca}^{2+}$, and $\mathrm{Mg}^{2+}$ in the wastewater from sewage treatment plant might drive to a gradual decrease of exchange capacity after some retention-regeneration processes due to the difficulty to remove those cations from zeolite by $\mathrm{Na}^{+}$exchange. To examine the recyclization of the synthesized zeolite, after a retention-regeneration process, the regenerative zeolite was further used to treat the wastewater from Tengzhou sewage treatment plant. The results in Table 6 showed that the regenerative zeolite also exhibited a good performance in ammonium removal, and had almost the same uptake capacity as its original zeolite.

\section{Conclusions}

Fly ash was converted into zeolite by a fusion method, as confirmed by XRD and SEM analyses. The major crystalline structure was identified as faujasite. CEC increased significantly from $0.033 \mathrm{meq} / \mathrm{g}$ of raw fly ash to $2.79 \mathrm{meq} / \mathrm{g}$ of synthesized zeolite after conversion. The optimal $\mathrm{pH}$ for ammonium uptake by the synthesized zeolite was found to be 8.0. To obtain the balance between ammonium adsorption capacity and removal efficiency, the optimum adsorbent dosage and initial ammonium concentration were found to be $1.32 \mathrm{~g} / \mathrm{L}$ and $167.89 \mathrm{mg} / \mathrm{L}$, respectively. The presence of individual cations and anions also influenced ammonium removal. The orders $\mathrm{K}^{+}>\mathrm{Ca}^{2+}>\mathrm{Na}^{+}>\mathrm{Mg}^{2+}$ for cations and $\mathrm{CO}_{3}^{2-}>\mathrm{Cl}^{-}>\mathrm{SO}_{4}^{2-}$ for anions were observed. The kinetics of ammonium uptake by the synthesized zeolite followed the Ho' pseudosecond-order model, suggesting that ion exchange was the ratecontrolling step. The rate constant was $1.44 \times 10^{-2} \mathrm{~g} \mathrm{mg}^{-1} \mathrm{~min}^{-1}$. The uptake data fit the Koble-Corrigan isotherm model best, indicating that heterogeneous and homogeneous uptake co-occurred for ammonium uptake by the synthesized zeolite. Thermodynamic studies revealed that the uptake of ammonium by the synthesized zeolite was exothermic in nature. At the synthesized zeolite dosage of $20 \mathrm{~g} / \mathrm{L}$, the ammonium concentrations in Class II effluent from sewage treatment plant met the Surface Water Environment Quality Standard GB38382002 IV after treatment. The regenerated zeolite had almost the same uptake capacity as original zeolite. This study shows that the synthesized zeolite was highly-efficient as an ion exchanger, and can be used to remove ammonium from municipal and industrial wastewater.

\section{Acknowledgements}

This work was supported by the National Water Special Project (No. 2009ZX07210-009-02), the National Science and Technology Support Project (No. 2006BAC10B03) and the National High Technology R\&D Program (2008AA06Z301).

Table 6

The performance of original zeolite and its regenerative zeolite in ammonium uptake in wastewater from sewage treatment plant $\left(\mathrm{T}=25^{\circ} \mathrm{C}\right.$; $\left.\mathrm{pH}=8.0\right)$.

\begin{tabular}{|c|c|c|c|c|c|c|c|}
\hline \multirow[t]{2}{*}{ Ammonium concentration } & \multirow[t]{2}{*}{ Index } & \multicolumn{6}{|c|}{ Zeolite dosage (g/L) } \\
\hline & & 2 & 4 & 6 & 8 & 12 & 20 \\
\hline \multirow[t]{2}{*}{$7.3 \mathrm{mg} \mathrm{N} / \mathrm{L}$} & Ammonium concentrations after treatment $(\mathrm{mg} / \mathrm{L})$ & 5.26 & 3.57 & 2.77 & 2.29 & 1.62 & 1.20 \\
\hline & Ammonium removal efficiency (\%) & 28.11 & 51.23 & 62.19 & 68.77 & 77.88 & 83.62 \\
\hline \multirow[t]{2}{*}{ Ammonium concentration } & Index & \multicolumn{6}{|c|}{ Regenerative zeolite dosage (g/L) } \\
\hline & & 2 & 4 & 6 & 8 & 12 & 20 \\
\hline \multirow[t]{2}{*}{$7.3 \mathrm{mg} \mathrm{N} / \mathrm{L}$} & Ammonium concentrations after treatment (mg/L) & 5.30 & 4.01 & 3.22 & 2.47 & 1.69 & 1.05 \\
\hline & Ammonium removal efficiency (\%) & 27.56 & 45.15 & 56.02 & 66.20 & 77.21 & 85.64 \\
\hline
\end{tabular}




\section{References}

[1] M. Sprynskyy, M. Lebedynets, R. Zbytniewski, J. Namieśnik, B. Buszewski, Ammonium removal from aqueous solution by natural zeolite, Transcarpathian mordenite, kinetics, equilibrium and column tests, Separation and Purification Technology 46 (2005) 155-160.

[2] H. Paerl, Doing battle with the green monster of taihu lake, Science 317 (2007) 1166.

[3] M. Yang, J.W. Yu, Z.H. Li, Z.H. Guo, M. Burch, T.F. Lin, Taihu lake not to blame for Wuxi's woes, Science 319 (2008) 158.

[4] D.J. Randall, T.K.N. Tsui, Ammonia toxicity in fish, Marine Pollution Bulletin 45 (2002) 17-23.

[5] Ministry of Environmental Protection of the People's Republic of China, Discharge standard of pollutants for municipal wastewater treatment plant, 2002.

[6] Y. Feng, Y.Z. Yu, Q.N. Duan, J. Tan, C.H. Zhao, The characteristic research of ammonium removal in grain-slag biological aerated filter (BAF), Desalination 263 (1-3) (2010) 146-150.

[7] D. Katehis, V. Diyamandoglu, J. Fillos, Stripping and recovery of ammonia from centrate of anaerobically digested biosolids at elevated temperatures, Water Environmental Research 70 (1998) 231-240.

[8] H.M. Baker, H. Fraij, Principles of interaction of ammonium ion with natural Jordanian deposits: analysis of uptake studies, Desalination 251 (2010) 41-46.

[9] S. Leaković, I. Mijatović, Š. Cerjan-stefanović, E. Hodšić, Nitrogen removal from fertilizer wastewater by ion exchange, Water Research 34 (2000) 185-190.

[10] D. Karadag, Y. Koc, M. Turan, B. Armagan, Removal of ammonium ion from aqueous solution using natural Turkish clinoptilolite, Journal of Hazardous Materials 136 (2006) 604-609.

11] H.M. Huang, X.M. Xiao, B. Yan, L.P. Yang, Ammonium removal from aqueous solutions by using natural Chinese (Chende) zeolite as adsorbent, Journal of Hazardous Materials 175 (1-3) (2010) 247-252.

[12] A. Thornton, P. Pearce, S.A. Parsons, Ammonium removal from solution using ion exchange on to MesoLite, an equilibrium study, Journal of Hazardous Materials 147 (3) (2007) 883-889.

[13] 4. Coal Ash Handbook, Kankyo Gijyutsu Kyokai and Nippon Fly ash Kyokai Tokyo, 2000.

[14] X. Querol, N. Moreno, J.C. Umaña, A. Alastuey, E. Hernández, A. López-Soler, F. Plana, Synthesis of zeolites from coal fly ash: an overview, International Journal of Coal Geology 50 (2002) 413-423.

[15] R.H. Juan, A Susana, J.M.R. Carmen, Ion exchange uptake of ammonium in wastewater from a sewage treatment plant by zeolitic materials from fly ash, Journal of Hazardous Materials 161 (2-3) (2009) 781-786.

[16] N. Murayama, S. Yoshida, Y. Takami, H. Yamamoto, J. Shibata, Simultaneous removal of $\mathrm{NH}_{4}^{+}$and $\mathrm{PO}_{4}^{3-}$ in aqueous solution and its mechanism by using zeolite synthesized from coal fly ash, Separation Science and Technology 38 (1) (2003) 113-129.

[17] D.Y. Wu, B.H. Zhang, C.J. Li, Z.J. Zhang, H.N. Kong, Simultaneous removal of ammonium and phosphate by zeolite synthesized from fly ash as influenced by salt treatment, Journal of Colloid and Interface Science 304 (2006) 300-306.

[18] C.F. Wang, J.S. Li, L.J. Wang, X.Y. Sun, J.J. Huang, Adsorption of dye from wastewater by zeolites synthesized from fly ash: kinetic and equilibrium studies, Chinese Journal of Chemical Engineering 17 (3) (2009) 513-521.

[19] N. Shigemoto, H. Hayashi, K. Miyaura, Selective formation of Na-X zeolite from coal fly ash by fusion with sodium hydroxide prior to hydrothermal reaction, Journal of Material Science 28 (1993) 4781-4786.
[20] A. Molina, C. Poole, A comparative study using two methods to produce zeolites from fly ash, Minerals Engineering 17 (2004) 167-173.

[21] F. Fotovat, H. Kazemian, M. Kazemeini, Synthesis of Na-A and faujasitic zeolites from high silicon fly ash, Materials Research Bulletin 44 (4) (2009) 913-917.

[22] J.G. Chen, H.N. Kong, D.Y. Wu, Z.B. Hu, Z.S. Wang, Y.H. Wang, Removal of phosphate from aqueous solution by zeolite synthesized from fly ash, Journal of Colloid and Interface Science 300 (2006) 491-497.

[23] Z.B. She, N.Z. Song, Processing and Application of Zeolites, Chemical industry press, Beijing, 2005.

[24] A. Moutsatsou, E. Stamatakis, K. Hatzitzotzia, V. Protonotarios, The utilization of Ca-rich and Ca-Si-rich fly ashes in zeolites production, Fuel 85 (2006) 657-663.

[25] A. Farkas, M. Rozic, Z. Barbaric-Mikocevic, Ammonium exchange in leakage waters of waste dumps using natural zeolite from the Krapina region, Croatia, Journal of Hazardous Materials 117 (1) (2005) 25-33.

[26] M. Sarioglu, Removal of ammonium from municipal wastewater using natural Turkish (Dogantepe) zeolite, Separation and Purification Technology 41 (1) (2005) 1-11.

[27] A.M. Yusofa, L.K. Keata, Z. Ibrahimb, Z.A. Majida, N.A. Nizamb, Kinetic and equilibrium studies of the removal of ammonium ions from aqueous solution by rice husk ash-synthesized zeolite $\mathrm{Y}$ and powdered and granulated forms of mordenite, Journal of Hazardous Materials 174 (2010) 380-385.

[28] L.C. Lei, X.J. Li, X.W. Zhang, Ammonium removal from aqueous solutions using microwave-treated natural Chinese zeolite, Separation and Purification Technology 58 (2008) 359-366.

[29] L.R. Weatherley, N.D. Miladinovic, Comparison of the ion exchange uptake of ammonium ion onto New Zealand clinoptilolite and mordenite, Water Research 38 (20) (2004) 4305-4312.

[30] Y. Wang, Y. Kmiya, T. Okuhara, Removal of low-concentration ammonia in water by ion-exchange using Na-mordenite, Water Research 41 (2007) 269-276.

[31] M. Ahmaruzzaman, D.K. Sharma, Adsorption of phenols from wastewater, Journal of Colloid and Interface Science 287 (2005) 14-24.

[32] S. Lagergren, About the theory of so-called adsorption of soluble substances, Hung Sven Veten Hand 24 (1898) 1-39.

[33] Y.S. Ho, G. McKay, Pseudo-second order model for sorption processes, Process Biochemistry 34 (1999) 451-465.

[34] W.J. Weber, J.C. Morris, Advances in water pollution research: removal of biologically resistant pollutants from waste waters by adsorption, Proceedings of the International Conference on Water Pollution Symposium 2 (1962) 231-266.

[35] I. Langmuir, The adsorption of gases on plane surfaces of glass, mica and platinum, Journal of America Chemistry Society 40 (1918) 1361-1367.

[36] H.M.F. Freundlic, Uber die adsorption in losungen, Zeitschrift fur Physikalische Chemie (Leipzig) 57A (1906).

[37] R.A. Koble, T.E. Corrigan, Adsorption isotherm for pure hydrocarbons, Industrial and Engineering Chemistry 44 (1952) 383-387.

[38] M.J. Tempkin, V. Pyzhev, Acta Physiochim, URSS 12 (1940) 217-222.

[39] M.M. Dubinin, L.V. Radushkevich, Equation of the characteristic curve of activated charcoal, Chemisches Zentralblatt 1 (1947) 875.

[40] K.R. Hall, L.C. Eagleton, A. Acrivos, T. Vermeulen, Pore and solid diffusion kinetics in fixed bed adsorption under constant pattern conditions, Industrial and Engineering Chemistry Fundamentals 5 (1966) 212-219.

[41] A. Demir, A. Gunay, E. Debik, Ammonium removal from aqueous solution by ion exchange using packed bed natural zeolite, Water SA 28 (3) (2002) 329-336. 